\title{
PROFESSORALIDADE E DESEMPENHO DOCENTE: UM OLHAR A PARTIR DOS RESULTADOS DA AVALIAÇÃO INSTITUCIONAL
}

\author{
PROFESSORIALISM AND TEACHING DEVELOPMENT: A VIEW FROM THE \\ RESULTS OF THE INSTITUTIONAL EVALUATION
}

\author{
PROFESORALIDAD Y DESEMPEÑO DOCENTE: UNA MIRADA DESDE LOS \\ RESULTADOS DE LA EVALUACIÓN INSTITUCIONAL
}

\author{
Daniela Pederiva Pensin ${ }^{1}$ Alexandra Biondo Lopes Pacheco ${ }^{2}$
}

\begin{abstract}
RESUMO
Este artigo toma como central a discussão acerca do processo de desenvolvimento da professoralidade docente na educação superior. Para isso, mobiliza teorizações ancoradas na perspectiva do campo da pedagogia universitária e dados decorrentes de pesquisa desenvolvida durante o ano de 2017, cujo objetivo foi avaliar os impactos que o desenvolvimento da professoralidade docente traz ao desempenho do professor nos processos de avaliação institucional interna. $\mathrm{O}$ projeto de pesquisa foi financiado por recursos públicos, originados no Programa de Bolsas Universitárias de Santa Catarina (Uniedu). A pesquisa realizada, um estudo de caso de caráter documental, tomou como materialidade os relatórios de avaliação do desempenho docente referentes ao período compreendido entre os anos de 2012 e 2016 de um dos campi de uma universidade comunitária localizada no oeste de Santa Catarina. Como resultados, destaca-se a pouca diferenciação entre os desempenhos docentes quando considerados: anos de docência, participação em formações pedagógicas continuadas e investimentos em formação acadêmica. O estudo reforça a percepção da professoralidade docente como um processo que extrapola a dimensão profissional técnica e traz condições de possibilidade para a problematização dos processos de subjetivação docente enquanto constitutivos da professoralidade. Os dados lançam luz sobre a necessidade de se continuar problematizando as práticas institucionais de avaliação do desempenho docente.
\end{abstract}

PALAVRAS-CHAVE: Professoralidade docente. Desempenho docente. Docência na Educação Superior.

\begin{abstract}
This paper is about the discussion over the process of the development of the teaching professorialism in high education. Thus, it handles theories upon the perspective of the field of university pedagogy and data from the survey made in 2017 , whose aim was evaluate the impacts that the development of the teaching professorialism brings to the development of the teacher in the processes of the intern institutional
\end{abstract}

\footnotetext{
${ }^{1}$ Doutora em Educação. Professora colaboradora do Programa de Pós-graduação em Educação da Universidade do Oeste de Santa Catarina
}

\footnotetext{
${ }^{2}$ Acadêmica do Curso de Pedagogia da Universidade do Oeste de Santa Catarina
}

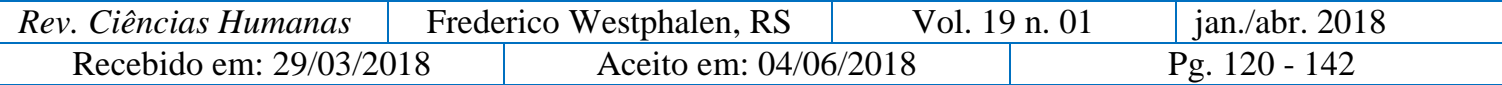




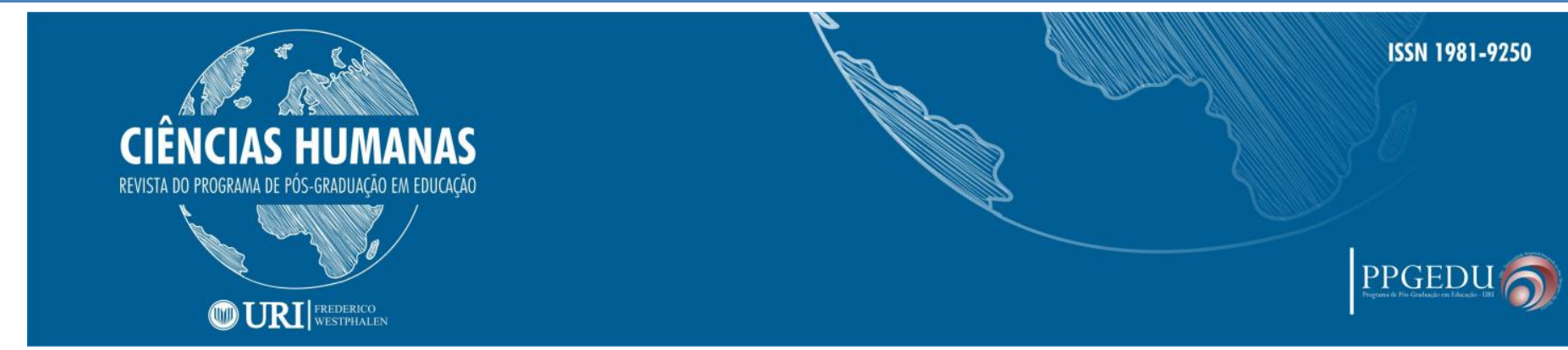

evaluation. The project of the survey was supported by public resources - Uniedu. The research - a documental study - had its materiality the reports of evaluation of teaching development between 2012 and 2016 in one of the campi of the community university in the west of the state of Santa Catarina. In the results we observe the little difference among the teaching development when it was considered: the amount of years in the teaching field, participation on continuing pedagogical development and the investment in the academic formation. The study reinforce the perception of the teaching professorialism as a process that infers the technical professional dimension and brings the possibility to think about the process of teaching subjectivity when they are part of the professorialism. The data shows the necessity of continuing thinking the institutional practices of evaluation of the teaching development.

KEYWORDS: Professorialism teaching. Teaching development. Teaching in higher education.

\section{RESUMEN}

Este artículo toma como central la discusión acerca del proceso de desarrollo de la profesoralidad docente en la educación superior. Para ello, moviliza teorizaciones ancladas en la perspectiva del campo de la Pedagogía Universitaria y datos derivados de investigación desarrollada durante el año 2017, cuyo objetivo fue evaluar los impactos que el desarrollo de la profesoralidad docente trae al desempeño del profesor en los procesos de evaluación interna. El proyecto de investigación fue financiado por recursos públicos, originados en el Programa de Bolsas Universitárias de Santa Catarina (Uniedu). La investigación realizada, un estudio de caso de carácter documental, tomó como materialidad los informes de evaluación del desempeño docente desde un período comprendido entre los años 2012 y 2016 de uno de los campus de una universidad comunitaria ubicada en el oeste de Santa Catarina. Como resultados, se destaca la escasa diferenciación entre los desempeños docentes cuando se consideran: años de docencia, participación en formaciones pedagógicas contínuas e investimientos en formación académica. El estudio refuerza la percepción de la profesoralidad docente como un proceso que extrapola la dimensión profesional técnica y trae condiciones de posibilidad para la problematización de los procesos de subjetivación docente en cuanto constitutivos de la profesoralidad. Los datos arrojan luz sobre la necesidad de continuar problematizando las prácticas institucionales de evaluación del desempeño docente.

PALABRAS CLAVE: Profesoralidad docente. Desempeño del docente. Enseñanza em la educación superior.

\section{CONSIDERAÇÕES INICIAIS}

A Lei de Diretrizes e Bases da Educação Nacional, Lei 9.394/96 (BRASIL, 1996), traz a universidade como locus da formação para a docência na educação superior. A ênfase da legislação, no entanto, recai sobre a formação acadêmica levando à compreensão de que esta formação tem, na titulação acadêmica stricto sensu, suficiente suporte à atuação do professor neste nível de ensino. Apoiadas em Powaczuk e Bolzan (2008), assumimos a premissa de que os professores, uma vez que não possuem formação específica para as atividades docentes do ensino superior, constituem-se como professores no decorrer do exercício de tal profissão. As práticas docentes e os muitos

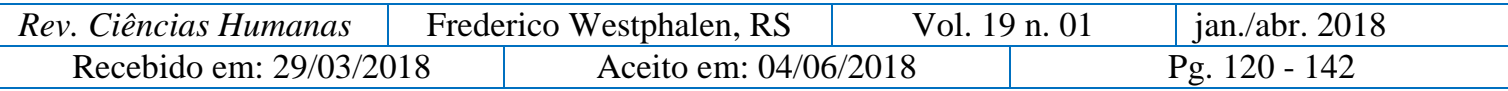




\section{CIÊNCIAS HUMANAS}

REVISTA DO PROGRAMA DE PÓS-GRADUAĞ̈O EM EDUCAĞ̄o

\section{(1) URI|}

estudos que tomam a questão como interesse apontam que a atuação do professor implica mais do que conhecimentos sobre a área de atuação profissional e demanda, em igual valor, conhecimentos de natureza pedagógica que envolvam as especificidades da educação superior assim como um conhecimento experiencial (TARDIF, 2003) sustentado pelo exercício profissional em si, pela partilha e pela colaboração na realização deste exercício.

Opera, na constituição daquilo que Isaia e Bolzan (2005) denominam professoralidade docente, também a dimensão pessoal. A professoralidade docente compreende um processo de constituição do profissional que envolve aspectos pessoais. Esta dimensão pessoal também se (re)faz a partir das práticas profissionais que, no caso do professor da educação superior, estão delimitadas e conduzidas fortemente pelos processos e práticas institucionais. Assim, no exercício da profissão, o professor desenvolve suas características profissionais e pessoais, o que leva à constituição de sua professoralidade e toma como referência as posições e práticas institucionais.

As discussões sobre a professoralidade docente partem do pressuposto de que a profissão docente envolve um processo que se constrói ao longo da trajetória formativa dos sujeitos professores que, vale destacar, não nascem professores e sim se constroem professores. Compreende a trajetória pessoal e profissional, sendo esta última atravessada pelos anos iniciais de formação, bem como pelo exercício continuado da docência. A professoralidade é, então, o processo de construção do sujeito professor, que se dá a partir de uma dimensão pessoal e de uma dimensão profissional e trama aspectos éticos, estéticos, epistemológicos, sociais, culturais e afetivos, entre outros, e espaços e tempos em que o professor se (re)constrói. Tal professoralidade mobiliza, entre seus desafios, o de fazer com que os professores continuem aprendendo, deliberadamente, ao longo de sua carreira, que compreendam a necessidade de engajarse na formação continuada (MARCELO GARCIA, 2009).

Consideramos importante indicar a necessidade de superação de uma visão mecânica e linear da construção da professoralidade docente. Ela, a professoralidade, envolve "sentimentos, relações, saberes de diferentes ordens, o individual e ao mesmo tempo o coletivo" (MENDES, BACCON, 2016, p.420). É, mesmo quando 


\section{CIÊNCIAS HUMANAS}

REVISTA DO PROGRAMA DE PÓS-GRADUAĞ̈O EM EDUCAĞ̄o

\section{(1) URI|}

consideramos e valorizamos sua singularidade, uma construção coletiva que demanda a presença e interação com o outro; o outro professor, o outro contexto institucional.

Cumprem as instituições de ensino superior (IES) papel central nos processos de constituição da docência quer seja desde o ponto de vista de serem espaço e território da docência, quer desde uma perspectiva legal que a aponta como responsável pela formação dos professores da educação superior (mesmo posta a formação acadêmica como ênfase, como já destacamos). Deste modo, necessitam prever estratégias, políticas, diretrizes institucionais voltadas à formação (pedagógica e acadêmica) de seus professores, de modo a qualificar a atuação destes que são, estrategicamente e em última instância, os responsáveis pela operacionalização dos compromissos formativos assumidos pelas IES, o que anuncia a necessidade de filiação destes aos propósitos institucionais. O planejamento e o pensamento estratégico voltado à promoção e ao desenvolvimento da professoralidade demandam a organização e a análise de dados sobre o desempenho do professor. Disso decorre a relevância dos dados da avaliação institucional que, entre outros dados institucionais, podem subsidiar ações de formação pedagógica continuada, orientadas inclusive para as diferentes etapas da vida docente, e também os investimentos em formação continuada de natureza acadêmica.

O texto que segue é o resultado de um projeto de pesquisa vinculado ao Grupo de Estudos e Pesquisas em Docência na Educação Superior (GEPDES), desenvolvido durante o ano de 2017 e que teve por objetivo avaliar os impactos que o desenvolvimento da professoralidade traz ao desempenho docente identificado pelos processos de avaliação institucional. O projeto de pesquisa foi financiado por recursos públicos, originados no Programa de Bolsas Universitárias de Santa Catarina (Uniedu). A pesquisa realizada, um estudo de caso de caráter documental, tomou como materialidade os relatórios de avaliação do desempenho docente referentes ao período compreendido entre os anos de 2012 e 2016 de um dos campi de uma universidade comunitária localizada no oeste de Santa Catarina.

Destacamos, antes de iniciarmos a exploração dos elementos teóricos e dos achados da pesquisa que, muito embora este seja um estudo de caso que tome como locus uma universidade jovem, localizada no interior do sul do país, caracterizada como 


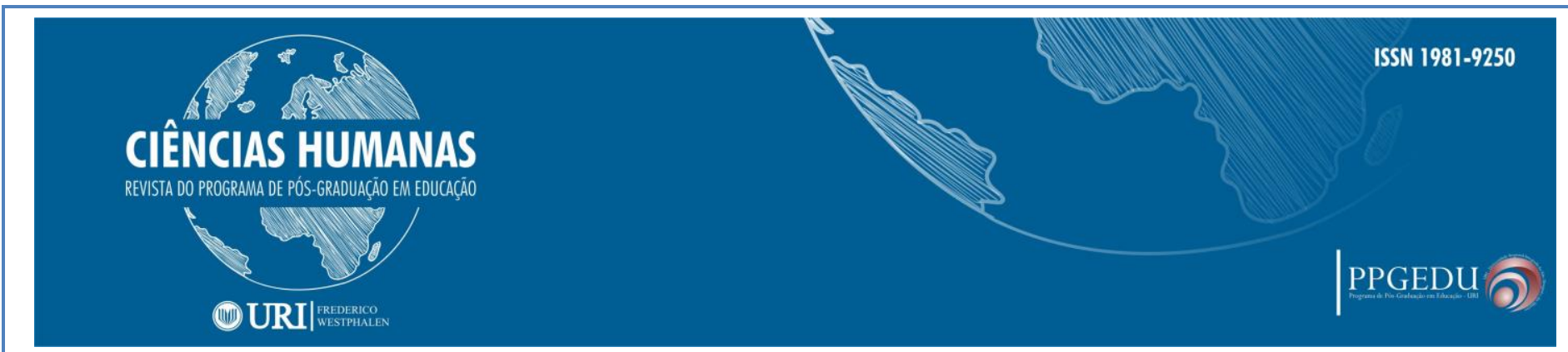

comunitária e cujos compromissos estão orientados ao desenvolvimento regional, esta "figura" apresenta-se, com pequenas alterações a distingui-las entre si, como recorrente entre muitas das universidades da Região Sul do Brasil, especialmente nos estados de Santa Catarina e Rio Grande do Sul.

\section{PROFESSORALIDADE DOCENTE}

Nesta seção pretendemos desenvolver questões relativas à constituição e à caracterização da docência na educação superior como uma ação complexa, possuidora de especificidade e cuja constituição detém caráter de singularidade. Na tentativa de trazer elementos que possam dar conta de um mínimo necessário para a compreensão do que assumimos em relação ao termo docência, trazemos os olhares de Isaia (2006), Cunha (2010) e Mendes e Baccon (2016).

Nas palavras de Isaia (2006, p. 374), a docência é tomada como ação que compreende as atividades desenvolvidas pelos professores, "orientadas para a preparação de futuros profissionais. Tais atividades são regidas pelo mundo da vida e da profissão, alicerçadas não só em conhecimentos, saberes e fazeres [...] o que indica [...] não se esgotar na dimensão técnica". Para Cunha (2010, p.20), a docência "se estrutura sobre saberes próprios, intrínsecos à sua natureza e a seus objetivos”, o que nos levaria ao reconhecimento de uma condição profissional para a atividade do professor que se dá como atividade complexa. Em consonância com Mendes e Baccon (2016), consideramos que a função docente se caracteriza pela ação de ensinar. Uma ação de ensinar que já não é, desde muito tempo, definível pela simples transmissão de conhecimentos e informações. Ser um profissional do ensino não é simples, afirmam as autoras, "pois é preciso levar em consideração que, além daquilo que se espera do papel do professor, existem diferentes fatores que contribuem para a construção da docência como profissão" (MENDES; BACCON, 2016, p.418).

Podemos afirmar então que a docência na educação superior se constitui na interação de diferentes processos que sustentam "o modo como os professores concebem o conhecer, o fazer, o ensinar e o aprender, bem como o significado que dão a eles" (ISAIA, 2006, p. 374). É, em nosso entendimento, uma forma de docência

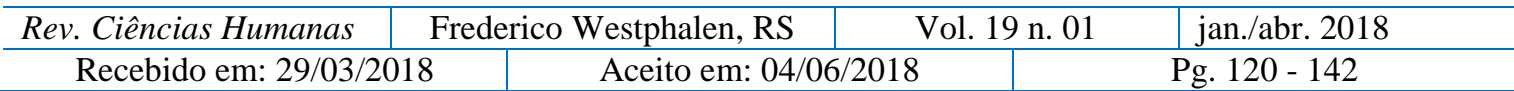




\section{CIÊNCIAS HUMANAS}

REVISTA DO PROGRAMA DE PÓS-GRADUAĞ̈O EM EDUCAĞ̄o

\section{(1) URI|}

específica. Tal posicionamento está apoiado nos elementos históricos e contextuais dos discursos sobre a docência que a fazem uma prática deste mundo, deste tempo e, portanto, diferente de outras formas de docência de outros tempos, outros contextos.

Como docência singular, a docência na educação superior (1) ocorre em uma instituição cuja ação educativa tem como pressuposto a profissionalização do indivíduo; (2) além da ação do ensino em si, opera sobre ela o imperativo da produção de conhecimento por meio de pesquisa acadêmica e socialização desse conhecimento; (3) o processo educativo com o qual se envolve mobiliza práticas de ensino orientadas ao adulto, cujas constituições cognitiva, social, cultural e afetiva, experiências e orientações ou objetivos são outros que não os do adolescente ou do infante (PENSIN, 2017).

No contexto da Pedagogia Universitária, a docência é uma ação complexa que precisa ser analisada "à luz das racionalidades que a caracterizam" (CUNHA, 2010, p.19), e há o reconhecimento de que essa ação se estruture sobre conhecimentos próprios. A docência, para essa lógica, está constituída por uma racionalidade pautada em saberes referentes: ao contexto da prática pedagógica; à dimensão relacional e coletiva dos processos de formação; à ambivalência da aprendizagem; ao contexto sócio-histórico dos alunos; ao planejamento das atividades de ensino; à condução da aula nas suas múltiplas possibilidades e à avaliação da aprendizagem (CUNHA, 2010). A docência envolve a possibilidade de ser uma profissão ou a condição daquilo que é tomado como profissão e apresenta três dimensões: a da obrigação moral, a do compromisso com a comunidade e a da competência profissional (MOROSINI, 2006). A multidimensionalidade aqui anunciada por Morosini (2006) e Cunha (2010) provoca pensar a professoralidade a partir da atividade realizada pelo sujeito para produzir-se como professor e que faz necessária a adoção de meios e procedimentos com vistas à assunção do ofício docente (ISAIA; BOLZAN, 2005).

Aprender a ser professor; este é um dos aspectos centrais do desenvolvimento da professoralidade docente e se inicia com o que Isaia e Bolzan (2008) chamam de empolgação pela docência. Na perspectiva apontada pelas autoras, esta pode ser entendida como a "mola propulsora" para o comprometimento em apreender a função 


\section{CIÊNCIAS HUMANAS}

REVISTA DO PROGRAMA DE PÓS-GRADUAĞ̈O EM EDUCAĞ̄o

\section{(1) URI|}

docente. Além de considerarem seus domínios específicos, os professores precisam de uma espécie de "tomada de consciência" quanto à necessidade de investimentos na dimensão pedagógica da docência. Ao terem consigo uma percepção lúcida e não romantizada acerca do papel que desempenham e da responsabilidade que possuem no contexto formativo em que atuam, os professores assumem protagonicamente a construção de sua professoralidade.

A constituição da professoralidade não abrange apenas os domínios dos saberes e fazeres, mas também a sensibilidade do docente como pessoa e profissional. Ao longo de suas carreiras os docentes da educação superior vão se envolvendo e protagonizando trajetórias profissionais e processos formativos cujos desafios enfrentados se dão desde a preparação para o ingresso na profissão até a constituição de sua professoralidade docente, decorrente de toda uma trajetória de desenvolvimento profissional e pessoal, tramada na complexidade da docência e a qual chega a partir de seu amadurecimento profissional.

Consideramos, coerentemente com os estudos do campo da Pedagogia Universitária, a formação continuada como um dos principais elementos de construção da carreira dos professores. Desenvolvida a partir de uma rede de convívios, diálogos e intermediações, propicia o desenvolvimento do processo de aprendizagem docente, promovendo maior aproximação entre os estudos teóricos e as práticas docentes cotidianas. Sobre esta questão, Isaia et al. (2008, p.3) relatam:

\footnotetext{
Acredita-se, pois, que se obtém um avanço sobre questões pedagógicas, à medida que se busca compreender as relações recíprocas existentes entre domínio do saber (conhecimento científico) e o domínio do fazer (conhecimento prático). Logo, o processo de pensamento do professor e suas formas de conceber e desenvolver o ensino explicita como este sistema de concepções pessoais, se desdobra, transformando-se em conhecimento pedagógico compartilhado.
}

É importante compreender a formação profissional como um processo contínuo que traz na reflexão do docente sobre sua prática, a contribuição para o desenvolvimento de suas habilidades e as iniciativas para prosseguir na busca de aperfeiçoamento, evolução e desenvolvimento, rumo à construção de sua identidade profissional. Considerando-se o elemento da formação continuada, as práticas

\begin{tabular}{l|l|l} 
Recebido em: 29/03/2018 & Aceito em: 04/06/2018 & Pg. 120 - 142
\end{tabular}




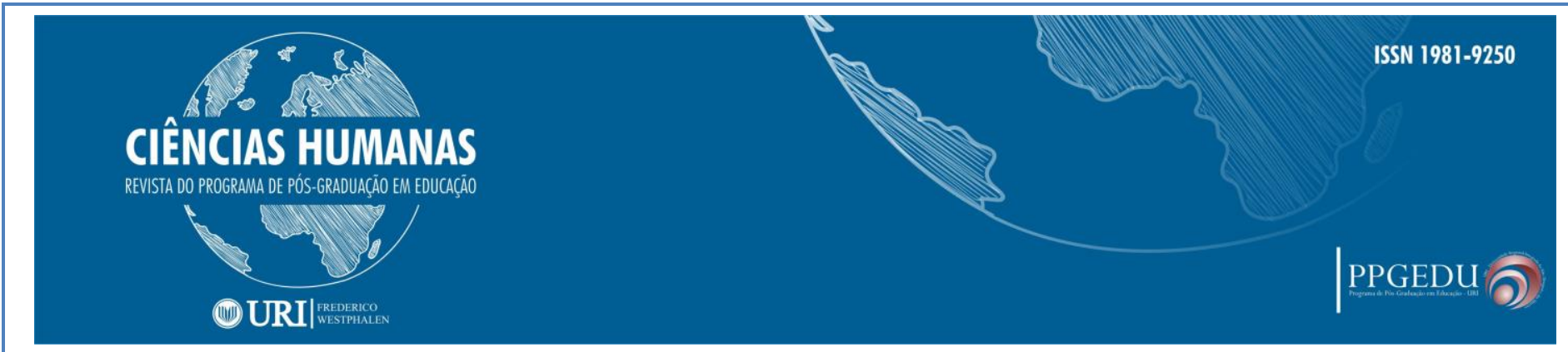

pedagógicas e a dimensão coletiva e colaborativa da docência, a noção de professoralidade docente é reforçada como um processo ininterrupto que envolve a formação inicial, o processo formativo em andamento, as redes de relações entre docentes, as teorias e práticas pedagógicas, a experiência adquirida nas instituições de ensino e as concepções pessoais sobre a profissão.

Reconhecemos que a formação do profissional, esta formação da e para a docência na educação superior, está intimamente ligada a uma atitude pessoal e é dependente das aspirações do professor, de sua vontade de buscar pela profissionalização e consequentemente construir sua carreira. Por outro lado, os contextos institucionais não podem ser desconsiderados quando falamos de construção da professoralidade docente. Lugar, espaço e território da docência universitária (CUNHA, 2010), as políticas e práticas institucionais estão intimamente implicadas nesta construção contínua, quase sempre de modo sistemático e organizado, como uma "intenção concreta por parte das instituições nas quais trabalham de criarem condições para que esse processo se efetive, possibilitando assim a construção de sua professoralidade" (ISAIA e BOLZAN, 2007, p.165).

Uma das políticas institucionais cujas práticas impactam significativamente o processo de constituição da professoralidade docente é a Avaliação Institucional. Inserida no contexto do Sistema Nacional de Avaliação da Educação Superior (SINAES) e conduzida pelas Comissões Próprias de Avaliação (CPAs) em cada IES, a avaliação docente se coloca como possibilidade de diagnóstico, reflexão e orientação para as metas e planejamentos institucionais. A avaliação docente construída nos processos de avaliação interna favorece aos gestores a análise de seus quadros docentes e aos professores a reflexão e (re)condução de suas práticas pedagógicas.

São os resultados da avaliação institucional, especificamente aqueles referentes às percepções dos alunos sobre o desempenho do professor e suas práticas docentes, indicativos a serem considerados nas políticas e ações institucionais. Fazendo eles referência às práticas de docência, inserem-se em processos de profissionalização docente e fazem ver características mais ou menos comuns a tempos mais ou menos definidos de docência, denominados por Isaia e Bolzan (2008) como fases da docência. 


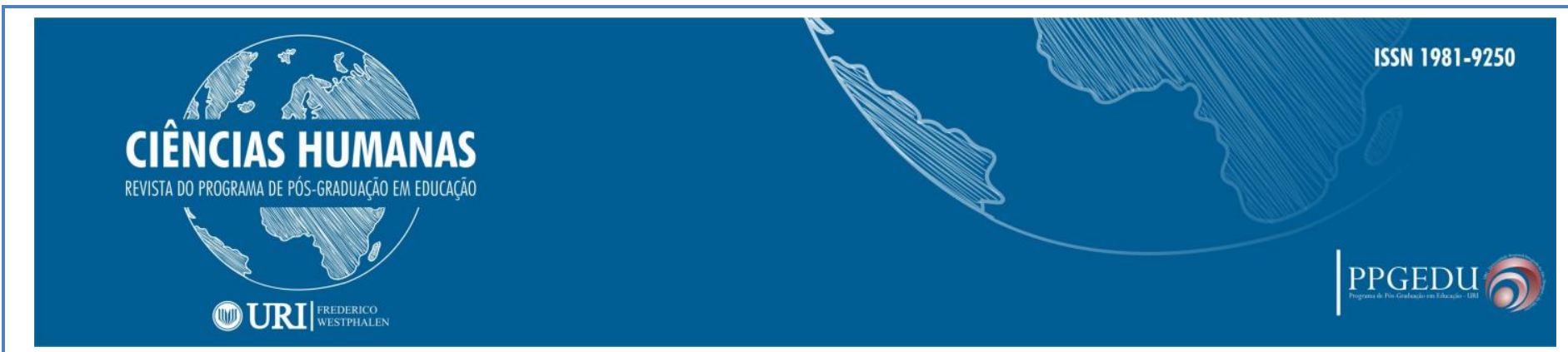

As fases constitutivas da carreira docente e sua vinculação com os caminhos percorridos pelo professor na construção de sua professoralidade exercem influência sobre a prática educativa dos professores. A forma como pensam e exercem a docência, modifica-se ao longo da carreira e apresenta componentes subjetivos, atravessados por expectativas, sentimentos, apreciações que acompanham a linha temporal da trajetória docente, constituindo assim, os ciclos ou fases da profissão (ISAIA; BOLZAN, 2008). Os ciclos de vida profissional dos docentes da educação superior, ou fases da docência, e os movimentos construtivos que acontecem durante estas fases, atuam como mecanismos de construção da carreira docente e da formulação de suas concepções de docência. O parâmetro central na definição dos ciclos/fases da docência são os anos de experiência profissional no magistério da educação superior. Com isso temos: anos iniciais (até 5 anos de docência), anos intermediários (de 6 a 15 anos de docência) e anos finais (a partir de 16 anos de docência).

Os movimentos construtivos da carreira docente na educação superior descritos pelas autoras partem de um momento de caráter "preparatório" que demonstra a iniciação na docência da educação superior. Tal movimento envolve diversos conhecimentos e experiências pedagógicas prévias que vão desde o ensino médio até a formação e pós-graduação lato sensu e stricto sensu. Este primeiro movimento poderia ser entendido como uma espécie de "mobilização para", o despertar de um interesse que se dá tomando como referências, muito fortemente, as experiências discentes com as quais se envolveu desde o final de sua escolarização básica.

O segundo movimento está demarcado pelo ingresso do docente no ensino superior e passa pelo que pode ser considerado momento de "efetivação da docência" em que a característica mais marcante é ciência da falta de preparação pedagógica para a docência neste nível específico de ensino (ISAIA; BOLZAN, 2008). Não são raros, neste momento, enfrentamentos, por parte do docente, de várias questões inerentes à sua prática, como insegurança quanto aos alunos e conteúdo, a se será possível atender toda a ementa, a ansiedade por querer vencer a disciplina no tempo estipulado, o despreparo para docência neste nível de ensino e o que ela espera do professor: atuação no ensino, 


\title{
CIÊNCIAS HUMANAS
}

REVISTA DO PROGRAMA DE PÓS-GRADUAĞ̈O EM EDUCAĞ̄o

\section{(1) URI|}

na pesquisa e na extensão. É neste momento que, com frequência, o docente vivencia o sentimento de "solidão pedagógica". Nas palavras de Isaia e Bolzan (2008, p. 49):

\begin{abstract}
A solidão pedagógica é sentida devido à inexistência tanto de apoio institucional ao professor, quanto da parte de colegas mais experientes. Cunhamos o termo solidão pedagógica para indicar o sentimento de desamparo dos professores frente à ausência de interlocução e de conhecimentos pedagógicos compartilhados para o enfrentamento do ato educativo.
\end{abstract}

Este segundo momento está colocado, muito embora o movimento das fases e entre elas não seja algo linear e mecânico, na fase dos anos iniciais da docência. É este um período em que a trajetória profissional docente é incipiente uma vez que os docentes são respaldados "por pendores naturais e ou em modelos de mestres que internalizaram em sua formação inicial, aliados aos conhecimentos advindos de determinado campo científico e da prática como profissionais em uma atividade específica que não a do magistério superior” (ISAIA; BOLZAN, 2006, p.491).

O terceiro movimento é o que leva o profissional à busca do aperfeiçoamento para a docência na educação superior através do ingresso em cursos de pós-graduação. Nestes cursos, além da formação para pesquisa, os docentes vão desenvolver conhecimentos sobre a prática pedagógico-formativa de sua função. As disciplinas específicas para a área pedagógica vão contribuir para o desenvolvimento das aulas, tanto no aspecto da didática como nas relações interpessoais com os alunos.

O último movimento construtivo da carreira docente denomina-se professoralidade docente (ISAIA; BOLZAN, 2008). Aqui a concepção de docência está mais madura, considera o aluno e seus interesses de aprendizagem tanto quanto as questões do ensino. Existe uma maior preocupação com a melhoria das práticas pedagógicas e um comprometimento com a formação dos alunos, o que quer dizer que o professor passa a "assumir conscientemente a condução pedagógica e colocar em marcha um processo de ação docente que favorece a aprendizagem dos alunos, preparando-os para seu aperfeiçoamento profissional" (ISAIA; BOLZAN, 2008, p.55).

Estes movimentos construtivos da docência não são lineares e não acontecem em sequência ou de acordo com períodos fixos de anos de carreira. O desenvolvimento da carreira constitui-se em "um processo e não em uma série de acontecimentos. Para 


\section{CIÊNCIAS HUMANAS}

REVISTA DO PROGRAMA DE PÓS-GRADUAĞ̈O EM EDUCAĞ̄o

\section{(1) URI|}

alguns, este processo pode parecer linear, mas para outros, há patamares, regressões, becos sem saída, momentos de arranque, descontinuidades" (HUBERMAN, 2000, p.38).

É de Huberman (2000) uma interessante caracterização frente aos ciclos de constituição da carreira docente na direção daquilo que estamos tomando por professoralidade. Em seus estudos, o autor encontrou recorrências no desenvolvimento da carreira do professor e as classificou em etapas básicas, de acordo com os anos de carreira: (1) entrada na carreira (um a três anos de docência): fase de sobrevivência, descoberta e exploração; (2) estabilização (quatro a seis anos): sentimento de competência e pertença a um corpo profissional; (3) diversificação ou questionamentos (sete a 25 anos): estágio de experimentação, motivação, busca de novos desafios e/ ou momento de questionamentos e reflexão sobre a carreira; (4) serenidade e distanciamento afetivo e/ou conservadorismo e lamentações ( 25 a 35 anos): pode levar ao conformismo ou ao ativismo; e (5), fase de desinvestimento, recuo e interiorização (35 a 40 anos): pode ser sereno ou amargo.

Ao tratar da docência como uma ação profissional que considera, em sua constituição, também aspectos pessoais e do contexto no qual se desenvolve e cujas características apresentam aproximações às práticas de docência presentes em um mesmo período de tempo, o objetivo não é o de promover o enquadramento do professor neste ou naquele ciclo de desenvolvimento profissional. Trata-se, isso sim, da possibilidade de encontrar, entre as recorrências nos resultados do desempenho docente expressos nas avaliações institucionais, elementos que possibilitem aproximar os professores por ciclos de desenvolvimento profissional e, com isso orientar políticas e projetos institucionais que possam atender mais assertivamente às demandas destes grupos.

\section{O CAMINHO METODOLÓGICO}

Tendo por objetivo avaliar os impactos que o desenvolvimento da professoralidade docente traz ao desempenho do professor, a pesquisa que dá corpo a este artigo, um estudo de caso de caráter documental, tomou como materialidade os 


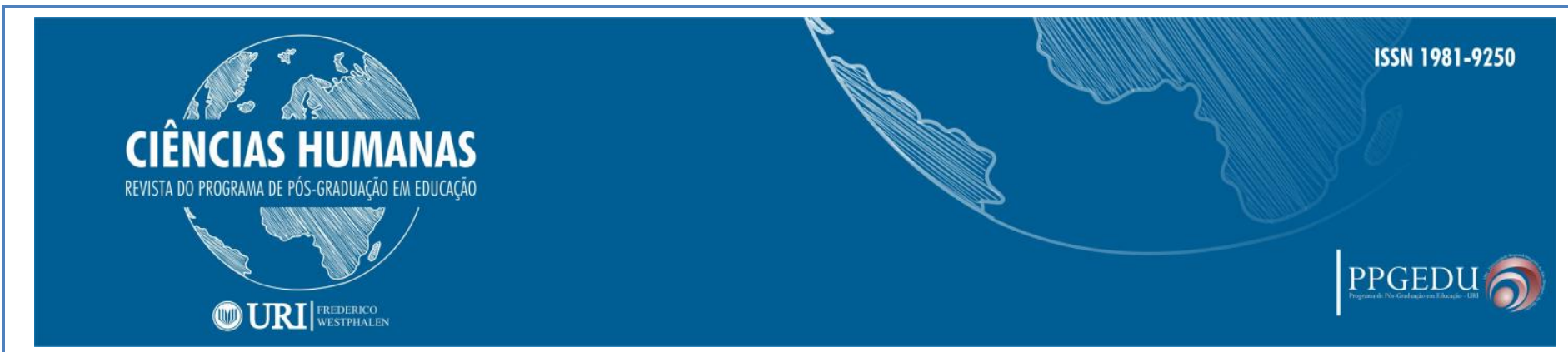

relatórios de avaliação do desempenho docente referentes ao período compreendido entre os anos de 2012 e 2016 de um dos campi de uma universidade comunitária localizada no oeste de Santa Catarina.

No semestre de referência para a pesquisa, 2017/1, o campus contava com 162 professores, distribuídos entre seus cursos. Para fins do levantamento de dados, estabelecemos como critérios de seleção dos sujeitos que fossem professores bacharéis com pelo menos 5 anos de atuação na docência na educação superior e cujas atividades docentes, correspondentes ao semestre 2017/1, estivessem vinculadas a um ou mais cursos de graduação das diferentes áreas do conhecimento ofertados no campus. Estavam enquadrados nesta caracterização 58 professores $(35,8 \%$ do total de professores). Buscando a exploração mais detalhada dos relatórios de avaliação interna referentes ao desempenho dos docentes nos processos de ensino, propusemos um recorte, tomando como amostra dez professores por área, considerando como área aquela de atuação predominante do professor em 2017/1. A área de ciências exatas e tecnológicas, uma área recente e que possui menos cursos ofertados no campus (portanto menos alunos e menos professores), teve sua representatividade reduzida a 05 (cinco) professores. Ficamos assim com um total de 25 (vinte e cinco) sujeitos de pesquisa. Este número representa $43,10 \%$ do número de sujeitos aptos a serem selecionados para o estudo. Foram considerados dados a média por professor referente aos resultados semestrais dos relatórios individuais de avaliação do desempenho docente referentes aos anos 2012, 2013, 2014, 2015 e 2016, o que traz um recorte temporal de 5 anos.

Um primeiro investimento na lida com os dados ocorreu na direção do levantamento e quantificação dos dados conforme os critérios acima descritos. Em seguida, passamos à alocação dos dados em categorias: (1) ciclos/fases de docência; (2) investimentos em formação pedagógica; (3) investimentos em formação acadêmica.

O passo seguinte compreendeu o levantamento individualizado dos dados decorrentes das avaliações internas sobre o desempenho do professor/disciplina na perspectiva do aluno. Para cada professor criamos uma pasta eletrônica onde foram salvas as avaliações por semestre. Entre os sujeitos pesquisados, 04 (quatro) não 


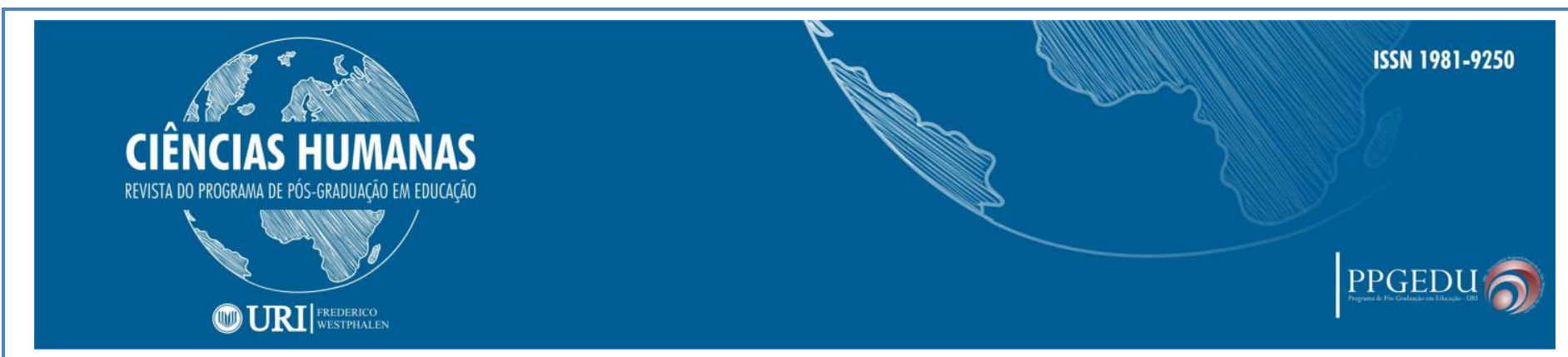

possuíam avaliações em alguns dos semestres, decorrente do fato de, naquele semestre especificamente, não estarem em atividade de docência mas manterem o vínculo com a instituição. Cabe indicar que algumas disciplinas, notadamente as de caráter prático como oficinas e estágios profissionais, nem sempre eram submetidas à avaliação institucional interna (o que estava dependente de decisões institucionais). Isto explica a ausência de avaliações para alguns professores em determinados semestres.

Evidentemente que a cada um dos professores decorre um número variável de avaliações semestrais. Visando equilibrar esta diferença, optamos por trabalhar com médias por professor/semestre. Assim, os professores passaram a ter médias semestrais para cada quesito avaliado pelos instrumentos de avaliação e uma média semestral geral. Após este primeiro trabalho, para cada um dos professores foi calculada a média final (decorrente da média das médias semestrais). Identificamos que dois tipos de questionários foram aplicados ao longo do período. Os questionários apresentam questões elaboradas de modo distinto uns dos outros, contudo, os quesitos avaliados permanecem e também o público respondente (estudantes) e o foco (a aula/disciplina professor) são mantidos. Por conta disso, foram extraídas uma média/professor por tipo de questionário. Ao longo da pesquisa os professores foram identificados pelos seus códigos funcionais, preservando assim suas identidades.

A organização dos dados obedeceu a uma classificação primária, qual seja, um grupo composto pelos professores da amostra melhores avaliados e outro grupo composto pelos professores da amostra piores avaliados no período. A IES adotou como meta, pautada pelas escalas de avaliação externa, a média 4,0 como desejável em todos os seus processos de avaliação interna. Isso inclui o desempenho dos professores que, neste sentido, deveriam manter-se nesta média ou acima dela. A partir desta classificação os dados foram organizados e analisados, tomando como orientação as perguntas de pesquisa: (1) o tempo de docência (em 2017/1) traz impacto no desempenho nas avaliações internas?; (2) qual o quesito (nas médias finais por questionário) em que se apresenta o melhor desempenho geral dos professores? Qual o pior?; (3) há alguma implicação/diferença relacionada ao fato de a avaliação ocorrer no 


\section{CIÊNCIAS HUMANAS}

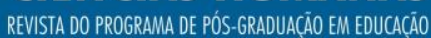

\section{(1) URI|}

primeiro ou no segundo semestre?; (4) Que características têm os professores que ficaram abaixo desta média?

A análise dos dados ocorreu orientada à avaliação dos impactos que o desenvolvimento da professoralidade docente trouxe ao desempenho do professor e suas relações com a formação pedagógica, as fases de docência e os investimentos na formação acadêmica do docente. Os achados da pesquisa, que emergem a partir da análise dos dados, são tratados a seguir.

\section{Os achados da pesquisa}

Os sujeitos da pesquisa constituem um grupo de 25 professores cuja inserção na docência na Instituição tem entre 5 e 19 anos. Consideradas as fases da docência assim definidas por Isaia e Bolzan (2008), há 1 professor na fase que as autoras denominam anos iniciais (compreendendo os primeiros 5 anos de docência), 16 professores nos anos intermediários (ou seja, em atividade docente entre 6 e 15 anos) e 8 professores na fase dos anos finais (com 16 anos ou mais de atividade docente). Esta caracterização dos sujeitos, majoritariamente alocados nos anos intermediários das fases da docência, parece-nos coerente com o contexto institucional: ser uma universidade localizada no interior do estado, jovem (seu credenciamento como universidade ocorreu em 1996) e cujo movimento de criação de cursos teve seu momento mais expressivo no período compreendido entre os anos de 2000 e 2005.

O campus tinha, em 2017/1, como corpo docente geral 29,86\% de especialistas, $50 \%$ de mestres e $20,14 \%$ de doutores. Aplicados os critérios para a composição da amostra deste estudo, os docentes especialistas passaram a corresponder a $48 \%$ dos sujeitos da pesquisa. Destes especialistas que fazem parte da amostra dos sujeitos investigados (12 professores), 6 estão na instituição/campus há 15 anos ou mais, indicando sua presença na fase dos anos finais da docência. Chama a atenção o fato de que tenham se mantido especialistas, que não tenham feito investimentos na continuidade de sua formação acadêmica muito embora desempenhem suas atividades docentes em uma IES universitária (o que pressupõe o desenvolvimento de ações 


\section{CIÊNCIAS HUMANAS}

REVISTA DO PROGRAMA DE PÓS-GRADUAĞ̈O EM EDUCAĞ̄o

\section{(1) URI|}

voltadas ao ensino, à pesquisa e à extensão como componentes da docência, elementos bastantes presentes nas formações stricto sensu).

Um dos elementos tomados para a análise na pesquisa foi o desempenho médio apresentado nos processos sistemáticos de Avaliação Institucional dos professores que se constituem sujeitos do estudo. Nesta direção, os dados apontam que não há diferenças significativas em relação aos semestres letivos em que as médias são analisadas, ou seja, no primeiro ou no segundo semestre letivo. Um possível desgaste físico, emocional e mental pelo qual passam professores e alunos ao longo do ano não tem, é o que indicam os dados, impactado na avaliação do desempenho dos professores.

Entre os sujeitos da pesquisa há relativo equilíbrio entre os professores que, em uma ou mais avaliações semestrais, apresentaram médias abaixo de 4,0 (quatro) - 14 professores ou $56 \%$ dos sujeitos (42\% deles são mestres, $42 \%$ especialistas e $14 \%$ doutores) - e aqueles que, no mesmo período, não apresentaram nenhuma média inferior a 4,0 (quatro) - 11 professores ou $44 \%$ dos sujeitos.

Quando olhamos para estes professores na perspectiva das fases da docência, vemos que nenhum deles está na fase inicial (até 5 anos), como era esperado dado o critério adotado para a composição da amostra, 9 (nove) estão na fase intermediária da docência e 5 (cinco) na fase final. Diante disso, é possível inferir que o pouco tempo de experiência não tem impactado negativamente no desempenho dos professores, assim como a experiência (em termos de anos de docência) não é determinante quanto ao que possa ser considerado "bom desempenho". Este dado reforça a necessidade já anunciada de se levar em consideração outros elementos que impactem a docência no contexto de sua professoralidade constituída por fatores profissionais e pessoais.

Mesmo que estes outros fatores (notadamente os de caráter subjetivo) não tenham sido objeto da pesquisa, indicamos a necessidade de se levar em consideração, por exemplo, o clima organizacional, as possibilidades de carreira, as condições de trabalho, a constituição e o sentido de equipe, o estímulo da coordenação de curso e dos colegas; além de fatores pessoais como personalidade, questões financeiras, problemas pessoais ou em seus locais de atuação fora da instituição (considerando o número de especialistas e o fato de se tratar de uma amostra composta por professores bacharéis, é provável que 


\section{CIÊNCIAS HUMANAS}

REVISTA DO PROGRAMA DE PÓS-GRADUAĞ̈O EM EDUCAĞ̄o

\section{(1) URI|}

haja um bom número destes professores atuando em ocupações profissionais fora da docência, no mercado de trabalho específico de sua profissão).

Para os professores avaliados (em todos os semestres analisados) com médias acima de 4,0 (quatro), o que se vê é a prevalência de professores nos anos intermediários da docência (ISAIA; BOLZAN, 2008): 7 (sete) dos 11 (onze) professores assim avaliados. Há, como podemos ver, um relativo equilíbrio na composição das fases da docência nos dois grupos. Nota-se no primeiro grupo, composto pelos professores que apresentaram, em um ou mais semestres avaliação abaixo de 4,0 (quatro), a presença de professores com mais tempo de atuação na Instituição. Mas é interessante observar que, tanto entre os professores com médias acima de 4,0 (quatro) quanto entre aqueles com médias inferiores a 4,0 (quatro), prevalecem os professores cujo tempo de docência os caracteriza como pertencentes à fase dos anos intermediários da docência.

A formação continuada de docentes é considerada por muitos estudiosos como elemento central na constituição da docência. As IES têm mobilizado, de modo mais intenso a partir da primeira década dos anos 2000, programas institucionais de formação pedagógica continuada. De modo distinto em cada IES, políticas de formação docente (quer orientadas à continuidade da formação acadêmica, quer com foco na formação pedagógica dos docentes) têm sido propostas, implementadas e avaliadas. A instituição tomada para fins deste estudo possui programas de formação pedagógica continuada e também políticas de formação continuada de natureza acadêmica. Sendo a formação continuada, nas duas dimensões aqui expostas, um importante elemento na constituição da professoralidade docente, buscamos dados que indicassem a participação dos sujeitos da pesquisa nas atividades institucionais de formação pedagógica continuada.

Mantida a análise em dois grupos distintos - a saber: (1) professores com uma ou mais médias de avaliação semestral abaixo de 4,0 e (2) professores com todas as médias semestrais de avaliação acima de 4,0) - em relação à participação nas atividades de formação pedagógica continuada o que se apresentou foi o seguinte:

QUADRO 1 - Horas de formação pedagógica continuada

\begin{tabular}{|l|l|l|}
\hline Ano & Grupo de professores & Média de horas de formação \\
\hline
\end{tabular}




\section{CIÊNCIAS HUMANAS}

REVISTA DO PROGRAMA DE PÓS-GRADUAĞ̈O EM EDUCAĢĀO

\section{(1)URI|}

\begin{tabular}{|c|c|c|}
\hline \multirow{2}{*}{2012} & & pedagógica continuada \\
\hline & 01 & 5,84 \\
\cline { 2 - 3 } & 02 & 5,45 \\
\hline \multirow{2}{*}{2013} & 01 & 4,30 \\
\cline { 2 - 3 } & 02 & 5,81 \\
\hline \multirow{2}{*}{2014} & 01 & 2,76 \\
\hline \multirow{2}{*}{2015} & 02 & 2,54 \\
\cline { 2 - 3 } & 01 & 4,0 \\
\hline \multirow{2}{*}{2016} & 02 & 4,36 \\
\cline { 2 - 3 } & 01 & 17,23 \\
\hline
\end{tabular}

Fonte: [as autoras, levantamento dos dados, pesquisa documental]

As horas de formação continuada ofertadas por ano, apresentam bastante variação no período analisado. Uma variação decorrente, muito provavelmente, de fatores institucionais como: organização do calendário institucional de atividades; demandas formativas emergentes; instituição de novas políticas no âmbito didático, de atuação docente, etc; disponibilidade dos docentes formadores em função da distribuição de suas cargas horárias nas diferentes funções (docentes e administrativas) que desempenhem; número de membros da equipe responsável pelo planejamento e oferta das formações, entre outros.

O olhar sobre as horas médias de formação pedagógica continuada realizadas pelos professores possibilita muitas reflexões. Uma delas se refere à pequena adesão à formação, o que pode ter, entre suas justificativas (1) a inadequação das temáticas, horários, períodos das formações ofertadas; (2) a incompreensão de que uma formação específica para a docência é requerida e valiosa para a atuação como professor da educação superior; (3) a inexistência ou fragilidade das políticas institucionais de formação docente ou ainda outros fatores.

No ano de 2016 o campus desenvolveu atividades de formação para as quais foram convocados professores. Isso surtiu efeito no implemento da carga horária de formação docente realizada pelos professores, como indicam os dados. Contudo, é possível questionar a eficácia de formações para as quais os professores não participem exatamente por vontade própria. Há estudos da área da Pedagogia Universitária, que ressaltam a importância de a formação pedagógica continuada ocorrer a partir da adesão voluntária do professor e não como uma ação para a qual ele é forçado. 


\section{CIÊNCIAS HUMANAS}

REVISTA DO PROGRAMA DE PÓS-GRADUAĞ̈O EM EDUCAĞ̄o

\section{(1) URI|}

Sob nosso olhar e considerando o foco da pesquisa, é importante refletir acerca dos dados que apontam para o fato de que os professores com melhores avaliações (aqueles que não receberam, em nenhum dos semestres analisados, avaliações médias inferiores a 4,0 (quatro)) não realizaram mais horas de formação pedagógica continuada do que aqueles cujas avaliações apresentaram, uma ou mais vezes, médias abaixo de 4,0 (quatro). Evidentemente este é um estudo que toma para si uma amostra, um recorte constituído por determinados sujeitos de pesquisa; estar ciente disso faz com que sejamos cuidadosos com generalizações e posicionamentos absolutos. A avaliação institucional não é exatamente um meio infalível de avaliar o desempenho dos professores. Manifestamos nossa incredulidade diante da possibilidade de que haja algum mecanismo ou instrumento capaz de avaliar, infalível e fielmente o desempenho docente. De algum modo, ela busca retratar em números o que nem sempre pode ser quantificado. Há o fator "aluno/avaliador" frequentemente implicado por resultados nas provas, empatia, referenciais pessoais e etc. Mesmo assim, é a avaliação institucional um instrumento que gera dados tornados oficiais e autorizados sobre, entre outros processos, os processos de ensino e de aprendizagem na instituição.

Retomando a questão da formação pedagógica continuada (aqui tomada em termos de horas e desconsiderando aspectos como temáticas e qualidade da formação), se esta não traz impacto direto sobre o desempenho do professor, então podemos pensar que outros elementos (pessoais e institucionais) sejam mais impactantes para a qualidade do trabalho do professor. Isso não desqualifica a formação docente, nem diminui sua importância, mas abre espaço para que outros elementos sejam considerados na relação da construção da professoralidade docente e suas relações com o desempenho do professor nos processos de avaliação institucional.

Considerando-se a importância de vinculação entre a formação pedagógica continuada e os dados da avaliação institucional, orientamos o olhar às temáticas de formação continuada (para isso acessamos os relatórios anuais das atividades de formação desenvolvidas) e aos quesitos que, na situação dos professores que apresentaram em um ou mais semestres médias inferiores a quatro (grupo 1) e na situação daqueles que, contrariamente, em nenhum semestre apresentaram médias 


\section{CIÊNCIAS HUMANAS}

REVISTA DO PROGRAMA DE PÓS-GRADUAĞ̈O EM EDUCAĞ̄o

\section{(10)URI|}

inferiores a quatro (grupo 2). Antes de entrarmos nesta questão, um esclarecimento: conforme já indicado, no período tomado para estudo (2012-2016) foram aplicados dois questionários diferentes direcionados à avaliação do desempenho dos professores pela perspectiva dos estudantes. Os aspectos avaliados são os mesmos, nos dois tipos de questionário. As mudanças estão orientadas à linguagem.

Os questionários foram olhados a partir das médias gerais (desempenho por professor ao longo de todos os semestres avaliados) por questionário (questionário $1 \mathrm{e}$ questionário 2, separadamente) quesito a quesito. Deste exercício resultou a indicação de dois quesitos que foram melhor avaliados (receberam as notas mais altas) considerando-se a média de desempenho entre todos os professores, por questionário. $\mathrm{O}$ mesmo foi feito com os dois quesitos que receberam as piores notas.

De modo geral, ou seja, tratando dos resultados gerais, sem separar os grupos de professores em relação aos seus desempenhos, este olhar sobre os quesitos melhores e piores avaliados trouxe informações sobre as quais, na sequência, trataremos de refletir. Considerando-se os dois questionários, os dois quesitos melhores avaliados têm em seu bojo (1) relações interpessoais em sala de aula e (2) o planejamento da aula e aproveitamento do tempo. Em termos de quesitos que receberam as piores avaliações estão apresentados (1) a indicação de estudos complementares, para além da sala de aula e (2) aquele que diz respeito ao incentivo à participação na avaliação institucional o que pode ser explicado por conta da pequena cultura de participação (mesmo por parte dos professores) nos processos de avaliação institucional.

A metodologia, especialmente em relação às estratégias e técnicas, não aparece entre os destaques positivos. Entre os aspectos metodológicos foram destacados negativamente estão a orientação de ampliação de estudos (indicado nos 2 questionários); a inadequação da metodologia (estratégias e recursos) para a compreensão dos conteúdos e ampliação dos conhecimentos (indicado nos 2 questionários). O que se vê, em termos de destaque positivo de metodologia, refere-se ao planejamento das aulas e ao aproveitamento do tempo.

Considerando-se os desempenhos nos dois questionários, nota-se pouca diferenciação entre os resultados dos professores melhores avaliados e os dos 


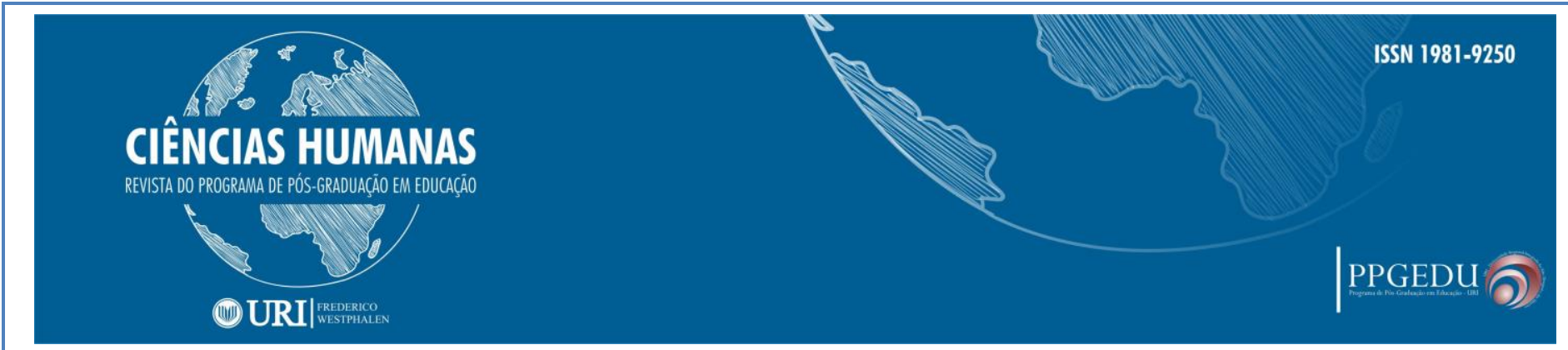

professores piores avaliados. Estas pequenas diferenciações sugerem que, muito embora haja professores melhores avaliados do que outros (em suas médias semestrais por questionário), aquilo que é apontado como positivo ou negativo em relação aos seus desempenhos se apresenta tanto entre os professores cujas médias de avaliação estão acima de 4,0 (quatro) quanto no grupo de professores que, em uma ou mais vezes, apresentou média abaixo de 4,0 (quatro). Potencialidade e fragilidades docentes se apresentam de modo muito semelhante entre os docentes dos dois grupos. Isso encontra eco na quase inexistente relação entre o desempenho docente nas avaliações institucionais e a participação dos professores nas atividades de formação continuada. Parece haver pouca distinção entre os professores quando tomados os elementos: participação formação continuada, tempos de docência e titulação. As fases da docência, inseridas num contexto de constituição da professoralidade docente, seriam, assim, implicadas mais significativamente por aspectos outros, que não estes. Possivelmente a dimensão subjetiva seja predominante entre estes "outros aspectos".

Os investimentos institucionais em formação pedagógica continuada compreenderam, no período 2012-2016, um total de 472 horas. Os projetos desenvolvidos no período foram organizados segundo o critério de aproximação por temáticas, de modo a constituírem categorias de formação assim distribuídas: (A) Introdução à docência (120 horas); Pesquisa/relação ensino e pesquisa (92 horas); (B) Técnicas, recursos e tecnologias educativas (51 horas); (C) Metodologias de ensino (107 horas); (D) Gestão (42 horas); (E) Relações interpessoais (36 horas) e (F) Outras/formação geral (24 horas). Os três professores que desenvolveram as maiores cargas horárias de formação continuada são mestres e estão na instituição há 10 anos ou mais.

Estes dados de modo algum questionam a importância ou o valor da formação pedagógica continuada para atuação na educação superior. Reforçamos a necessidade de formação para a docência, a apropriação de saberes próprios de um campo de especificidades como condição ao exercício da docência na educação superior. O que nos parece é que os dados resultantes deste esforço de investigação são indicativos da necessidade de se repensar as políticas institucionais de formação pedagógica 


\section{CIÊNCIAS HUMANAS}

REVISTA DO PROGRAMA DE PÓS-GRADUAĞ̈O EM EDUCAĞ̄o

\section{(1) URI|}

continuada e o processo de construção da professorallidade docente e questionar, em ambos, a presença ou o silenciamento da dimensão subjetiva, pessoal, da singularidade do sujeito que, complexa e coletivamente, "faz" a docência: o professor.

\section{CONSIDERAÇÕES FINAIS}

A mirada sobre a materialidade da pesquisa, os relatórios individuais de avaliação institucional sobre o desempenho docente, trouxe indicativos importantes para a problematização da professoralidade docente e questionamentos sobre as relações que se estabelecem entre o desempenho dos professores (na perspectiva dos estudantes), a formação pedagógica continuada e a continuidade da formação acadêmica dos professores. Destacamos, como resultante da análise dos dados, a pouca diferenciação dos desempenhos docentes quando considerados: anos de docência, participação em formações pedagógicas continuadas e investimentos em formação acadêmica.

Ficou evidenciada a necessidade de se aprofundar estudos e ações formativas no âmbito das IES que tomem como objeto os processos de subjetivação docente. Também ficam indicativos da importância da dimensão pessoal na construção da professoralidade docente e a necessidade de se pensar este processo a partir de dados quantitativos e qualitativos. Ou seja, o estudo reforçou a percepção da professoralidade docente como um processo que extrapola a dimensão professional técnica e traz condições de possibilidade para a problematização dos processos de subjetivação docente enquanto constitutivos da professoralidade. Os dados lançam luz, ainda, sobre a necessidade de se seguir problematizando as práticas institucionais de avaliação do desempenho docente.

\section{REFERÊNCIAS}

BRASIL. Lei N. 9394, de 20 de dezembro de 1996. Estabelece as diretrizes e bases da Educação Nacional. Ministério da Educação, Brasília, DF, 20 dez. 1996. Disponível em: < $\leq$ http://portal.mec.gov.br/arquivos/pdf/ldb.pdf $\geq$. Acesso em: 11 abril 2017. 


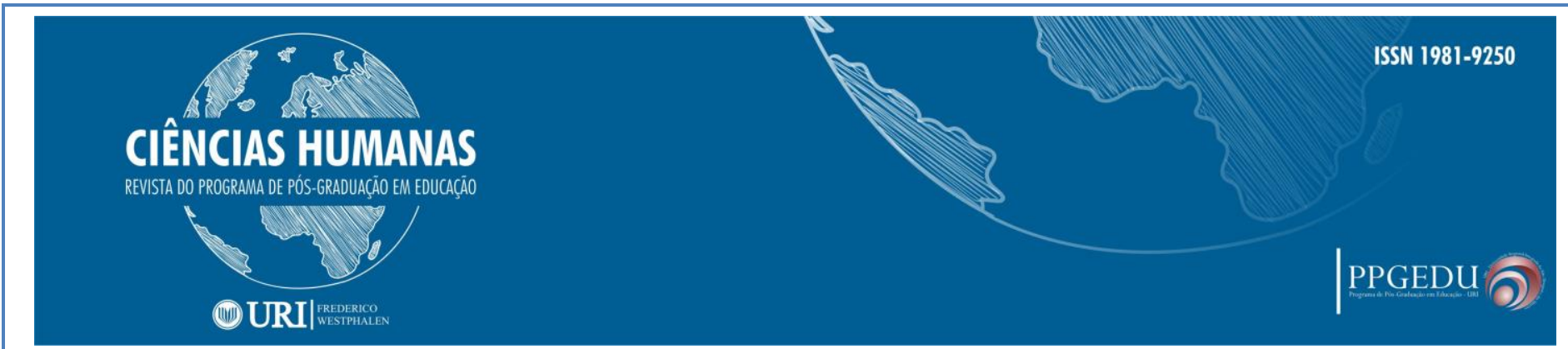

CUNHA, Maria Isabel da (Org). Trajetórias e lugares da formação da docência universitária: da perspectiva individual ao espaço institucional. Araraquara: Junqueira \& Marin. Brasilia: CAPES: CNPq, 2010.

HUBERMAN, M. O ciclo de vida profissional dos professores. In: NÓVOA, A. (Org.). Vidas de professores. 2. ed. Porto: Porto, 2000. p.31-61.

ISAIA, Silvia Maria de Aguiar. Docência Superior. In: MOROSINI, Marilia Costa (Org). Enciclopédia de Pedagogia Universitária: Glossário. v. 2. Porto Alegre: INEP/RIES, 2006.

ISAIA. Silvia; BOLZAN. Doris Pires Vargas. Aprendizagem Docente no Ensino Superior: construções a partir de uma rede de interações e mediações. UNIrevista. Vol.1, n.1. IV Congresso Internacional de Educação. UNISINOS. São Leopoldo. 2005.

ISAIA, S.; BOLZAN, D. P. V. Construção da profissão docente/professoralidade em debate: desafios para a educação superior. In: CUNHA, M. I. (Org.). Reflexões e práticas em pedagogia universitária. Campinas: Papirus, 2007. p. 161-177.

ISAIA, Silvia Maria de Aguiar; BOLZAN, Doris Pires Vargas. Compreendendo os movimentos construtivos da docência superior: construções sobre pedagogia universitária. Linhas Críticas, Brasília, v. 14, n. 26 .p. 43-59, jan./jun. 2008. Disponível em: http://periodicos.unb.br/index.php/linhascriticas/article/view/1551/1181. Acesso em: 20 mar. 2018.

ISAIA, Silvia Maria Aguiar et al. Educação superior e aprendizagem docente: a construção da professoralidade. Santa Maria, UFSM, 2008. (Paper) Disponível em: < http://w3.ufsm.br/gtforma/estagio1/5f8279f686111670e4d47b33350b3be9.pdf>. Acesso em: 21 mar. 2018.

MARCELO GARCIA, C. Desenvolvimento profissional docente: passado e futuro.

Sísifo, Lisboa, n. 8, jan./abr. 2009. Disponível em:

http://www.fep.porto.ucp.pt/sites/default/files/files/FEP/SAME/docs/Carlosmarcelo_De senv_Profissional.pdf $>$. Acesso em: 10 out. 2014.

MENDES, Thamiris Christiane e BACCON, Ana Lucia Pereira. Profissional docente: o ser e o manter-se na docência. In: PRYJMA, Marielda Ferreira e OLIVEIRA, Oséias Santos de (orgs). O desenvolvimento profissional docente em questão. Curitiba: Ed.UFTPR, 2016. p. $416-433$.

MOROSINI, Marilia Costa. Enciclopédia de Pedagogia Universitária: Glossário. v. 2. Porto Alegre: INEP/RIES, 2006. 610 p. 


\section{(10URI|}

PENSIN, Daniela Pederiva. Agenciamento e docência na educação superior. São Leopoldo: Unisinos, 2017. 204p. Tese (Doutorado em Educação) — Universidade do Vale do Rio dos Sinos, São Leopoldo, 2017.

POWACZUK, Ana Carla e BOLZAN, Doris Pires Vargas. Docência em caráter substitutivo: lugar de aprendizagem docente no ensino superior. Políticas Educativas, Campinas, v. 1, n.2, p.62-74, jul. 2008.

TARDIF, Maurice. Saberes docentes e formação profissional. Petrópolis: Vozes, 2003. 